\title{
Preface for the special issue of the 3rd KACST-Oxford Petrochemical Forum
}

\author{
Peter P. Edwards $\cdot$ Hamid Almegren • \\ Tiancun Xiao • Vladimir Kuznetsov
}

Published online: 13 May 2014

(c) The Author(s) 2014. This article is published with open access at Springerlink.com

\begin{abstract}
The 3rd KACST-Oxford Petrochemical Research Forum (KOPRC Forum) was held in August 2013, some of the presentations in the forum have been submitted to the special issue of Applied Petrochemical Research. This paper collection covers most of topics of petrochemical technologies including catalyst and catalytic process, polymers, feedstocks and process improvements.
\end{abstract}

Keywords Preface $\cdot$ KOPRC Forum - Oxford $\cdot$ KACST

2. Natural petroleum and its resulting petrochemicals yield the ubiquitous fuels for the world's transportation and heating as well as a myriad of other products to sustain the quality of life that the developed and, increasingly, the emerging economies demand. Products originating from petroleum constitute more than $95 \%$ of the worlds manufactured goods and touch virtually every aspect of our modern life, from basic human needs such as food, water, clothing, housing and transportation all the way to the latest advances in health care, communications and information technology.

Enhancing and optimising both energy and chemical product generation from fossil hydrocarbon fuels not only makes sound economic sense for petrochemical technologies, but also takes account of growing environmental and

P. P. Edwards $(\bowtie) \cdot$ T. Xiao · V. Kuznetsov

Inorganic Chemistry Laboratory, Oxford University, South Parks Road, Oxford OX1 3QR, UK

e-mail: peter.edwards@chem.ox.ac.uk

H. Almegren

Materials Research Institute, King Abdulaziz City for Science and Technology, P. O. Box 6086, Riyadh 11442, Kingdom of Saudi Arabia sustainability concerns, as strongly reflected in increasing regulatory requirements. Notwithstanding the maturity of the industry as a whole, the scale and extent of these diverse and critical challenges highlight the urgent need for a 'renaissance' approach—a 'repowering' approach-to advance new, innovative-and potentially nonconventional-petroleum petrochemical technologies that reduce both capital and operating costs whilst at the same time reduce energy consumption and environmental impact.

We believe that these critical goals can be accelerated by transformational science giving rise to strategic technologies for improving the efficiency by which fossil fuels are extracted, recovered and ultimately transformed into products. As the world's largest oil reserve country and the world's largest oil supplier, Saudi Arabia takes scientific and technological innovations in the petrochemical technologies very seriously. ${ }^{1}$

The establishment of the King Abdulaziz City of Science and Technology (KACST)-Oxford Petrochemical Research Centre (KOPRC) in 2010 was specifically designed to focus on these issues. Since that time, three KACST-Oxford Petrochemical Forums have been held in either Riyadh or Oxford. This special issue is a collection of some of the papers presented in the 3rd KOPRC Forum held in Wadham College, Oxford from 12th to 15th August 2013.

The Forum was focussed on potential "tipping point" ideas and advances to stimulate real, disruptive innovation in a mature, but receptive petroleum

\footnotetext{
1 'Strategic Priorities for Petrochemicals Technology Program', King Abdulaziz City for Science and Technology, and the Kingdom of Saudi Arabia Ministry of Economy and Planning http://www.mep. gov.sa.
} 
refining and petrochemical industry. The themes included the following overarching areas:

The Need, and Prospects, for Innovation and Nonconventional Technologies.

Catalysis Innovation - Innovative materials and advanced characterisation techniques.

Process Innovation: Upgrading petroleum heavy crude oil and residues.

Innovation for Environmental Sustainability.

We were honoured to be welcomed to Oxford by presentations from Sir Chris Llewellyn-Smith, FRS (Director of Energy Research, University of Oxford and President, SESAME Council, Sir David King, FRS (UK Special Representative for Climate Change, Foreign \& Commonwealth Office), and Professor Alex Halliday, FRS (Head of Mathematical and Physical Sciences, University of Oxford) and we thank those speakers and the other $50+$ lecturers and participants for their thoughtful, constructive and stimulating talks and interactive discussions.

All scientific contributions to the Forum have been peer reviewed through processes administered by the Scientific Committee. Reviews were conducted by international experts before accepted for publication. This special issue covers the subject areas of novel fuel resources, fine and specialty chemicals, catalysts and catalytic reactions, sustainable energy development and chemistry and chemical engineering, energy, polymer science and engineering and energy conservation and future trends in both technology and regulations.

We are grateful to all authors for their submissions to this conference and for sharing the information and experience they have acquired. We also thank Noemi Julio and Thomas Tschech of Springer for their professionalism and support in assembling and producing this volume. Last, but certainly not least, we thank all of our colleagues in both KACST and Oxford for all of their hard work in bringing about this important event. None more so than Linda Webb for her tremendous professionalism in all aspects of this endeavour. We would also like to thank KACST for their generous financial support for the 2013 Forum.

We are delighted to welcome you to next Forum to be held in Riyadh in 2014 !

Open Access This article is distributed under the terms of the Creative Commons Attribution License which permits any use, distribution, and reproduction in any medium, provided the original author(s) and the source are credited. 